\title{
Relationships of Lead, Mercury and Cadmium Levels with the Timing of Menarche among Korean Girls
}

\author{
Hye Seon Choi \\ Assistant Professor, College of Nursing, Woosuk University, Wanju, Korea
}

Purpose: This study utilized data from the Korean National Health and Nutrition Examination Survey (KNHANES) to explore differences in the timing of menarche in Korean girls according to blood heavy metal concentrations. Methods: This study performed a secondary analysis of cross-sectional data from the sixth KNHANES. Data from 179 female children and adolescents aged 10 18 were included in this study. The relationships of blood heavy metal concentrations (lead, mercury, and cadmium) with age of menarche were analyzed using complex sample multiple logistic regression. Results: In the participants of this study, the geometric mean values of blood lead, mercury, and cadmium concentrations were $1.15 \pm 0.04 \mu \mathrm{g} / \mathrm{dL}, 1.80 \pm 0.08 \mu \mathrm{g} / \mathrm{L}$, and $0.30 \pm 0.03 \mu \mathrm{g} / \mathrm{L}$, respectively. Mercury poisoning $(>5 \mu \mathrm{g} / \mathrm{L})$ was found in $1.5 \%$ of participants. Furthermore, significant relationships were found between blood lead and mercury concentrations and age at menarche ( $p$ for trend: $p<.001$ and $p=.015$, respectively). Conclusion: Through an analysis of national big data, this study found evidence that Korean girls showed a younger age at menarche in response to higher blood lead and mercury concentrations. To prevent and manage precocious puberty in Korean children and adolescents, a systematic policy that monitors both exposure to environmental hazards and blood heavy metal concentrations is needed.

Key words: Child; Lead; Menarche; Mercury; Puberty precocious

\section{Corresponding author Hye Seon Choi \\ https://orcid.org/0000-0003-4834-2723}

College of Nursing, Woosuk University,

443 Samnye-ro, Samnye-eup, Wanju 55338, Korea

TEL +82-63-290-1628 FAX +82-63-290-1548

E-MAIL hschoi@woosuk.ac.kr

*This study was supported by the research fund of Woosuk University in 2019.

Received Dec 14, 2019 Revised Dec 31, 2019 Accepted Jan 8, 2020
(9) This is an Open Access article distributed under the terms of the Creative Commons Attribution NonCommercial License (http://creativecommons org/licenses/by-nc/4.0/) which permits unrestricted noncommercial use, distribution, and reproduction in any medium, provided the original work is properly cited.

\section{INTRODUCTION}

In many countries, rapid industrialization has caused severe and hazardous contamination of soils with heavy metals, as well as particulate matter pollution. Soil contamination with heavy metals and air pollution have emerged as major global concerns, since they are deleterious for the environment and pose potential risks for human health [1,2]. Heavy metals are widely dispersed in the environment; in addition to being present in soil, they can also be found on the ground surface, in groundwater, in the air, and in other settings relevant for human life [3]. Heavy metals enter the body via respiration, skin contact, and oral ingestion of contaminated foods. The most common route of contamination is the consumption of crops grown in soil contaminated with heavy metal [1]. Inhalation is also an important route, as tiny particulate matter in the air-often so small as to be invisible without a microscope-may readily enter the lungs through the respiratory system $[2,4]$.

After entering the body, heavy metals form complexes with other substances within the body; as a result, they are not easily eliminated, and tend to accumulate [5]. Heavy metal accumulation results in a variety of harmful effects, which are es- 
pecially severe in children and adolescents [6]. Developing bodies are especially vulnerable to heavy metal exposure. Of particular concern, children inhale proportionally more air than adults, and their respiratory system filters hazardous materials less efficiently than that of adults because they engage in mouth breathing more frequently [6]. Moreover, the absorption rate of heavy metals through the digestive system is higher in children than in adults, and children's cumulative exposure may be higher if the duration of exposure extends to adulthood [6]. Furthermore, puberty-accompanied by the development of secondary sexual characteristics-is an important developmental stage in adolescence. Previous studies have reported both positive and negative relationships between blood lead, mercury, and cadmium concentrations and sexual development [7-11]. Therefore, the issue of heavy metal exposure in children and adolescents requires particular attention.

In recent years, particulate matter in the air has become a matter of grave concern in Korea. In 2015, the media mentioned particulate matter 254,913 times, which spiked 2.7-fold in just 2 years to 676,312 times in 2017 [12]. Particulate matter itself contains pollutants, including heavy metals [4]. Another relevant public health issue in Korea is the rising prevalence of precocious puberty. According to data from the Korean Health Insurance Review Agency [13], in the last 5 years, the number of patients with precocious puberty increased by $42.4 \%$ from 72,246 in 2014 to 102,886 in 2018. In particular, there were 11,099 boys with precocious puberty and 91,787 girls in 2018, with 8.27 times more girls than boys [13]. Precocious puberty refers to a phenomenon in which pubertal development occurs abnormally earlier and more quickly compared to other children of the same age [14]. In general, a girl is diagnosed with precocious puberty if she develops secondary sexual characteristics younger than the age of 8 (breast bud development at $<8$ years old; pubic hair development at $<9$ years old; menarche at $<9 \sim 10$ years old) [14]. Overall, precocious puberty has become a social issue in Korea, and the high prevalence of precocious puberty in girls has become an even more serious problem.

Until recently, most research on heavy metal elements has focused on the correlations of blood heavy metal concentrations with food ingestion [15] and children's products [16]. Earlier research related to precocious puberty placed a greater emphasis on the diagnosis and treatment of precocious puberty [14], the characteristics of precocious puberty, and psychosocial issues [17]. Research conducted to explore relationships between precocious puberty and heavy metal exposure in Korea is relatively rare. Additionally, previous studies have reported no significant relationships $[18,19]$ and even opposite findings regarding the relationship between sexual development and heavy metal concentrations [8-11,20], and these discrepancies underscore the necessity of further research. Moreover, fine dust in Korea is affected by yellow dust in China [4]. According to a recent Chinese study, a significantly earlier age at menarche was found in women with high blood cadmium levels [11]. Therefore, it is necessary to explore differences in the timing of menarche in Korean girls according to blood heavy metal concentrations.

Traditionally, the onset of menstruation has been considered the most significant indicator of sexual maturity in girls [21]. Thus, by analyzing data from the Korean National Health and Nutrition Examination Survey (KNHANES), which contains representative data on the nutritional status of the entire Korean population [22], we explored differences in the timing of menarche according to blood heavy metal concentrations, considering that age at menarche is a major parameter used to diagnose precocious puberty.

\section{METHODS}

\section{Study Design}

This study performed a secondary analysis of the sixth KNHANES to investigate the correlation between age at menarche and blood heavy metal concentrations in Korean girls [22].

\section{Sampling Procedure and Participants}

This study used the first-year data of the sixth KNHANES, which is being conducted with the approval of the Institutional Review Board of the Korea Centers for Disease Control and Prevention (KCDC) (Approval No. 2013-07CON-03-4C) [22]. Permission was also obtained from the Research Ethics Committee of W University (Approval No. WS-2019-19) and KCDC website (http://knhanes.cdc.go.kr/). This study used a nationally representative sample from the sixth KNHANES, 2013 2015. This national survey has been conducted annually since 2005 by the KCDC. The KNHANES comprises health questionnaires, examinations, and nutritional surveys [22]. The participants with information on heavy metal concentrations included 2,000 people who were over the age of 20 in 2005, 2008, and 2009; these participants accounted for one-half of the sample who were over the age of 10 in 2010 2013, and one-third of the sample who were over the age of 10 in 2017. The city of Sejong was added to the strata and cluster variables starting in 2016 [22]. For the purpose of this study, the dataset from the 2013 2015 KNHANES was used.

The first-year data of the sixth KNHANES included an examination of heavy metal exposure (lead, mercury, and cadmium) among 2,355 subjects (female: 1,178 and male: 1,177) 
[22]. The subjects of this study were female children and adolescents aged between 10 and 18, and the final analysis included 179 girls who underwent tests of blood heavy metal concentrations (lead, mercury, and cadmium).

The variables analyzed in this study were gender, age, economic status, residential area, housing type, age at menarche, height, body weight, body mass index (BMI), and blood heavy metal concentrations (lead, mercury, and cadmium) [22]. Previous studies have identified differences in blood heavy metal concentration according to socioeconomic status, residential area, and life environment $[11,23]$. In particular, children living in areas with lower socioeconomic status and poor living conditions had significantly higher blood lead levels than children living in the opposite environment (lower socioeconomic status and good living conditions) $[6,20,23]$. Therefore, this study used the variables of economic status, residential area, and housing type.

\section{Measures}

\section{1) General characteristics}

The KNHANES health survey items were used to analyze subjects' general characteristics including, age, economic status (household income quartile), residential area, housing type, height, body weight, and BMI. Age, economic status, housing type, age at menarche, height, body weight, and BMI were analyzed according to the raw data [22]. The residential areas of participants were reclassified from 16 cities into five regions: the capital area (Seoul, Incheon, and Gyeonggi Province); the Chungcheong area (Daejeon and North and South Chungcheong Provinces); the Daegu, Gyeongbuk, and Gangwon area (Daeju, North Gyeongsang Province, and Gangwon Province); the Busan, Ulsan, and Gyeongnam area (Busan, Ulsan, and South Gyeongsang Province); and the Honam and Jeju area (Gwangju, North and South Jeolla Provinces, and Jeju). This study used raw data with 1-year variation; the age at menarche was indicated using the international age [22]. The age of 10 years, the diagnostic criterion for premature menarche [14], was the earliest age of menarche considered in this study since it was the age when examinations of blood heavy metal levels were started. This study also used the same ranges of age at menarche as the KNHANES data, in which participants were categorized into the early-maturing group $(<11$ years), the average-maturing group (11 13 years), and the late-maturing group ( $\geq 14$ years) $[14,22]$.

\section{2) Blood heavy metal concentrations}

Lead and cadmium concentrations in blood were measured with graphite furnace atomic absorption spectroscopy using a Perkin Elmer AAnalyst 600. Mercury concentrations in blood were measured with inductively coupled plasma-mass spectrometry (ICP-MS) using a Perkin Elmer ICP-MS device [22]. Blood concentrations of lead and cadmium were categorized according to the standards presented in the Centers for Disease Control and Prevention (CDC) guideline, while the human biomonitoring (HBM) standard was used for mercury [22].

\section{Data Analysis}

All data were analyzed with two-sided tests using SPSS version 24 at a significance level of $\alpha=.05$. Complex sampling analysis was used to analyze the weighted data in compliance with the guidelines for utilizing KNHANES data [22]. General characteristics are presented as frequency and percentage, whereas complex sampling descriptive statistics (mean and standard deviation) were used for age at menarche, height, body weight, BMI, and blood heavy metal concentrations. Age at menarche according to participants' demographic characteristics was analyzed with the $x^{2}$ test and one-way ANOVA analysis of variance considering the complex sample design. Age at menarche was categorized as 10, 11, 12, 13 and $\geq 14$ years to examine the relationships between blood concentrations of heavy metals and menarche. The blood concentrations of heavy metals were analyzed using a complex sample multiple logistic regression with lead, mercury, and cadmium levels as the dependent variables.

\section{RESULTS}

\section{Participant Demographics and Characteristics}

The subjects of this study were all females, with a mean age of 14.4 years. Their economic status was distributed as follows: mid-high, 32.2\%; high, 27.4\%; mid-low, 25.4\%; and low, $15.0 \%$. The vast majority of participants (48.3\%) lived in the capital area. Furthermore, $57.3 \%$ and $42.7 \%$ of participants lived in apartments (flats) and houses, respectively. The mean age at menarche was 12.2 years. The participants' mean height and body weight were $158.7 \pm 0.6 \mathrm{~cm}$ and $53.4 \pm 0.9 \mathrm{~kg}$, respectively, and their mean BMI was $21.08 \pm 0.27 \mathrm{~kg} / \mathrm{m}^{2}$ (Table 1 ).

\section{Differences in Age at Menarche by Participants' Charac- teristics}

There were no significant differences in economic status, residential area, housing type, body weight, or BMI among the participants whose age at menarche was 10 years, 11 years, 12 years, 13 years, or $\geq 14$ years, but height showed a significant difference across these groups $(\mathrm{F}=3.54, p=.008)$ (Table 2$)$. 
Table 1. Participants' Characteristics

\begin{tabular}{|c|c|c|c|}
\hline Characteristics & Categories & $\mathrm{n}^{*}$ or $\left(\%^{\dagger}\right)$ & $\mathrm{M}^{\dagger}\left(\mathrm{SE}^{\dagger}\right)$ \\
\hline Age (year) & & & $14.4(0.2)$ \\
\hline Economic status $^{\dagger}$ & $\begin{array}{l}\text { Low } \\
\text { Mid-low } \\
\text { Mid-high } \\
\text { High }\end{array}$ & $\begin{array}{l}27(15.0) \\
44(25.4) \\
53(32.2) \\
53(27.4)\end{array}$ & \\
\hline Residential area & $\begin{array}{l}\text { Capital area }^{\S} \\
\text { Chungcheong area } \| \\
\text { Daegu, Gyeongbuk, and Gangwon area } \\
\text { Busan, Ulsan, and Gyeongnam area } \\
\text { Honam and Jeju area** }\end{array}$ & $\begin{array}{l}92(48.3) \\
22(13.2) \\
19(10.3) \\
22(14.7) \\
24(13.5)\end{array}$ & \\
\hline Housing type & $\begin{array}{l}\text { House } \\
\text { Apartments (flats) }\end{array}$ & $\begin{array}{r}76(42.7) \\
103(57.3)\end{array}$ & \\
\hline Age at menarche (year) & & & $12.2(0.1)$ \\
\hline Height (cm) & & & $158.7(0.6)$ \\
\hline Body weight (kg) & & & $53.4(0.9)$ \\
\hline BMI $\left(\mathrm{kg} / \mathrm{m}^{2}\right)$ & & & $21.08(0.27)$ \\
\hline
\end{tabular}

*Unweighted; ${ }^{\dagger}$ Weighted; ${ }^{\dagger}$ Excludes participants who did not reply; ${ }^{\S}$ Seoul, Incheon, and Gyeonggi Province; ${ }^{\|}$Daejeon and North and South Chungcheong Provinces; "Daeju, North Gyeongsang Province, and Gangwon Province; "Busan, Ulsan, and South Gyeongsang Province; ** Gwangju, North and South Jeolla Provinces, and Jeju; BMI=Body mass index.

Table 2. Differences in Age at Menarche by Participants' Characteristics

$(N=179)$

\begin{tabular}{|c|c|c|c|c|c|c|c|c|}
\hline \multirow{3}{*}{ Variables } & \multirow{3}{*}{ Categories } & \multicolumn{7}{|c|}{ Age at menarche } \\
\hline & & 10 years & 11 years & 12 years & 13 years & $\geq 14$ years & \multirow[b]{2}{*}{$x^{2}$ or $\mathrm{F}$} & \multirow[b]{2}{*}{$p$} \\
\hline & & $\begin{array}{c}\%^{*} \text { or } \\
\mathrm{M}(\mathrm{SE})^{\dagger}\end{array}$ & $\begin{array}{c}\%^{*} \text { or } \\
\mathrm{M}(\mathrm{SE})^{\dagger}\end{array}$ & $\begin{array}{c}\% * \text { or } \\
\mathrm{M}(\mathrm{SE})^{\dagger}\end{array}$ & $\begin{array}{c}\% * \text { or } \\
\mathrm{M}(\mathrm{SE})^{\dagger}\end{array}$ & $\begin{array}{c}\%^{*} \text { or } \\
\mathrm{M}(\mathrm{SE})^{\dagger}\end{array}$ & & \\
\hline \multirow{4}{*}{$\begin{array}{l}\text { Economic } \\
\text { status }^{\dagger}\end{array}$} & Low & 2.2 & 24.1 & 43.8 & 27.1 & 2.8 & \multirow[t]{4}{*}{11.24} & \multirow[t]{4}{*}{.619} \\
\hline & Mid-low & 3.1 & 17.1 & 27.4 & 25.8 & 26.6 & & \\
\hline & Mid-high & 2.5 & 22.3 & 36.1 & 15.1 & 24.0 & & \\
\hline & High & 3.7 & 15.0 & 36.9 & 13.9 & 30.5 & & \\
\hline \multirow{5}{*}{$\begin{array}{l}\text { Residential } \\
\text { area }\end{array}$} & Capital area ${ }^{\S}$ & 1.5 & 22.6 & 31.9 & 15.2 & 28.8 & \multirow[t]{5}{*}{15.51} & \multirow[t]{5}{*}{.706} \\
\hline & Chungcheong area $\|$ & 7.7 & 8.5 & 37.4 & 34.5 & 11.9 & & \\
\hline & Daegu, Gyeongbuk, and Gangwon area & 0.0 & 14.3 & 28.9 & 22.1 & 34.7 & & \\
\hline & Busan, Ulsan, and Gyeongnam area & 2.9 & 19.3 & 38.8 & 24.0 & 15.0 & & \\
\hline & Honam and Jeju area** & 5.7 & 20.4 & 42.8 & 15.1 & 16.0 & & \\
\hline \multirow{2}{*}{$\begin{array}{l}\text { Housing } \\
\text { type }\end{array}$} & House & 3.6 & 19.3 & 29.4 & 22.8 & 24.9 & \multirow[t]{2}{*}{1.92} & \multirow[t]{2}{*}{.820} \\
\hline & Apartments (flats) & 2.5 & 18.9 & 38.8 & 17.7 & 22.1 & & \\
\hline \multicolumn{2}{|l|}{ Height (cm) } & $160.2(3.0)$ & $159.8(1.2)$ & $158.6(0.9)$ & $161.3(1.2)$ & $154.1(1.6)$ & 3.54 & .008 \\
\hline \multicolumn{2}{|c|}{ Body weight (kg) } & $56.1(3.7)$ & $54.8(1.9)$ & $54.2(1.5)$ & $55.1(1.8)$ & $49.3(1.8)$ & 1.90 & .112 \\
\hline \multicolumn{2}{|l|}{ BMI $\left(\mathrm{kg} / \mathrm{m}^{2}\right)$} & $21.24(1.74)$ & $21.38(0.57)$ & $21.50(0.52)$ & $21.14(0.51)$ & $20.18(0.46)$ & 1.09 & .361 \\
\hline
\end{tabular}

${ }^{*}$ Weighted; ${ }^{\dagger}$ Weight mean, standard error and reference variable is 13 years; ${ }^{\dagger}$ Excludes participants who did not reply; ${ }^{8}$ Seoul, Incheon, and Gyeonggi Province; "Daejeon and North and South Chungcheong Province; "Daeju, North Gyeongsang Province, and Gangwon Province; "Busan, Ulsan, and South Gyeongsang Province; **Gwangju, North and South Jeolla Provinces, and Jeju; BMI=Body mass index.

\section{Blood Heavy Metal Concentrations}

Table 3 shows differences in blood heavy metal concentrations according to participants' characteristics. There were statistically significant differences in geometric mean values according to residential area (lead: $\mathrm{F}=3.21, p=.014$ ) and age at menarche (lead: $\mathrm{F}=7.10, p<.001$, mercury: $\mathrm{F}=3.17, p=.015$ ). However, there were no significant differences in the geome- 
tric mean values of blood lead, mercury, and cadmium according to economic status or housing type (Table 3).

In the participants of this study, the geometric mean values of blood lead, mercury, and cadmium concentrations were $1.15 \pm 0.04 \mu \mathrm{g} / \mathrm{dL}, 1.80 \pm 0.08 \mu \mathrm{g} / \mathrm{L}$, and $0.30 \pm 0.03 \mu \mathrm{g} / \mathrm{L}$, respectively. Mercury poisoning ( $>5 \mu \mathrm{g} / \mathrm{L})$ was found in $1.5 \%$ of participants (Table 3).

\section{Blood Heavy Metal Concentrations According to Age at Menarche}

In the participants of this study, significant relationships were found between blood lead and mercury concentrations and age at menarche ( $p$ for trend: $p<.001$ and $p=.015$, respectively). Higher blood lead and mercury concentrations were associated with a significantly lower age at menarche (Table 4).

\section{DISCUSSION}

The blood heavy metal concentrations observed in this study in Korean girls were higher than those generally reported in children from other major advanced nations. In this study, the geometric mean of blood lead concentrations in girls between
10 and 18 years of age was $1.15 \mu \mathrm{g} / \mathrm{dL}$, according to our analysis of KNHANES 2013 data. In contrast, in the National Health and Nutrition Examination Survey (NHANES) in the United States (US) [24], the average lead concentration was $0.57 \mu \mathrm{g} / \mathrm{dL}$ in participants between 6 and 11 years of age (2013 2014), and $0.51 \mu \mathrm{g} / \mathrm{dL}$ among those 12 to 19 years of age (2013 2014). According to the Canadian Health Measures Survey (CHMS) [25], the geometric mean of lead concentrations was 0.71 $\mu \mathrm{g} / \mathrm{dL}$ in children 6 to 11 years of age (2012 2013) and 0.64 $\mu \mathrm{g} / \mathrm{dL}$ in those 12 to 19 years of age (2012 2013). In this study, the geometric mean of blood mercury concentrations was 1.80 $\mu \mathrm{g} / \mathrm{L}$, which was significantly higher than the concentrations reported in children in the US and Canada, which were $0.33 \mu \mathrm{g} / \mathrm{L}$ (6 11 years, 2011 2012), $0.41 \mu \mathrm{g} / \mathrm{L}(12 \sim 19$ years, 2013 2014) in the NHANES data [24], and 0.28 $\mu \mathrm{g} / \mathrm{L}$ (6 11 years, 2009 2011) and $0.27 \mu \mathrm{g} / \mathrm{L}$ (12 19 years, 2009 2011) in the CHMS data [25]. The geometric mean of blood cadmium concentrations was $0.30 \mu \mathrm{g} / \mathrm{L}$ in this study, which was also significantly elevated relative to the levels reported in the US and Canada, which were $0.13 \mu \mathrm{g} / \mathrm{L}(12 \sim 19$ years, 2013 2014) in the NHANES data [24], and $0.10 \mu \mathrm{g} / \mathrm{L}(6 \sim 11$ years, 2009 2011) and $0.17 \mu \mathrm{g} / \mathrm{L}$ (12 19 years, 2009 2011) in the CHMS data [25]. As shown above, Korean girls' blood heavy metal concentrations were

Table 3. Differences in Blood Heavy Metal Concentrations by Participants' Characteristics

$(N=179)$

\begin{tabular}{|c|c|c|c|c|c|c|c|}
\hline \multirow{3}{*}{ Variables } & \multirow{3}{*}{ Categories } & \multicolumn{6}{|c|}{ Blood heavy metal concentrations } \\
\hline & & \multicolumn{2}{|c|}{ Lead $(\mu \mathrm{g} / \mathrm{dL})$} & \multicolumn{2}{|c|}{ Mercury $(\mu \mathrm{g} / \mathrm{L})$} & \multicolumn{2}{|c|}{ Cadmium $(\mu \mathrm{g} / \mathrm{L})$} \\
\hline & & $\mathrm{GM}(\mathrm{SE})^{*}$ & $\mathrm{t}$ or $\mathrm{F}(p)$ & $\mathrm{GM}(\mathrm{SE})^{*}$ & t or $\mathrm{F}(p)$ & $\mathrm{GM}(\mathrm{SE})^{*}$ & $\mathrm{t}$ or $\mathrm{F}(p)$ \\
\hline Economic status $^{\dagger}$ & $\begin{array}{l}\text { Low } \\
\text { Mid-low } \\
\text { Mid-high } \\
\text { High }\end{array}$ & $\begin{array}{l}1.10(0.09) \\
1.22(0.08) \\
1.21(0.07) \\
1.03(0.06)\end{array}$ & $\begin{array}{l}1.90 \\
(.132)\end{array}$ & $\begin{array}{l}1.77(0.17) \\
1.60(0.09) \\
1.74(0.11) \\
2.07(0.24)\end{array}$ & $\begin{array}{l}1.32 \\
(.269)\end{array}$ & $\begin{array}{l}0.30(0.04) \\
0.33(0.08) \\
0.28(0.03) \\
0.28(0.02)\end{array}$ & $\begin{array}{l}0.23 \\
(.878)\end{array}$ \\
\hline Residential area & $\begin{array}{l}\text { Capital area }{ }^{\ddagger} \\
\text { Chungcheong area }^{\S} \\
\text { Daegu, Gyeongbuk, and Gangwon area } \\
\text { Busan, Ulsan, and Gyeongnam area } \\
\text { Honam and Jeju area }\end{array}$ & $\begin{array}{l}1.22(0.06) \\
0.94(0.06) \\
1.05(0.10) \\
1.15(0.10) \\
1.20(0.11)\end{array}$ & $\begin{array}{l}3.21 \\
(.014)\end{array}$ & $\begin{array}{l}1.72(0.13) \\
1.60(0.14) \\
1.67(0.16) \\
2.20(0.26) \\
1.94(0.17)\end{array}$ & $\begin{array}{l}1.38 \\
(.243)\end{array}$ & $\begin{array}{l}0.27(0.02) \\
0.28(0.05) \\
0.25(0.03) \\
0.46(0.13) \\
0.28(0.05)\end{array}$ & $\begin{array}{l}0.66 \\
(.619)\end{array}$ \\
\hline Housing type & $\begin{array}{l}\text { House } \\
\text { Apartments (flats) }\end{array}$ & $\begin{array}{l}1.21(0.06) \\
1.11(0.06)\end{array}$ & $\begin{array}{l}1.35 \\
(.246)\end{array}$ & $\begin{array}{l}1.67(0.08) \\
1.90(0.13)\end{array}$ & $\begin{array}{l}2.20 \\
(.140)\end{array}$ & $\begin{array}{l}0.34(0.05) \\
0.27(0.02)\end{array}$ & $\begin{array}{l}1.30 \\
(.257)\end{array}$ \\
\hline $\begin{array}{l}\text { Age at menarche } \\
\text { (year) }\end{array}$ & $\begin{array}{l}10 \\
11 \\
12 \\
13 \\
\geq 14\end{array}$ & $\begin{array}{l}1.10(0.18) \\
1.08(0.07) \\
1.19(0.08) \\
1.07(0.07) \\
1.35(0.03)\end{array}$ & $\begin{array}{l}7.10 \\
(<.001)\end{array}$ & $\begin{array}{l}2.14(0.48) \\
1.64(0.22) \\
1.72(0.12) \\
2.03(0.27) \\
2.11(0.10)\end{array}$ & $\begin{array}{l}3.17 \\
(.015)\end{array}$ & $\begin{array}{l}0.44(0.09) \\
0.28(0.03) \\
0.30(0.03) \\
0.41(0.10) \\
0.32(0.02)\end{array}$ & $\begin{array}{c}1.21 \\
(.310)\end{array}$ \\
\hline \multicolumn{2}{|l|}{ Total } & \multicolumn{2}{|c|}{$1.15(0.04)$} & \multicolumn{2}{|c|}{$1.80(0.08)$} & \multicolumn{2}{|c|}{$0.30(0.03)$} \\
\hline \multicolumn{2}{|c|}{ Poisoning rate weighted $\% * *$} & \multicolumn{2}{|c|}{0.0} & \multicolumn{2}{|c|}{1.5} & \multicolumn{2}{|c|}{0.0} \\
\hline
\end{tabular}

*Weighted; ${ }^{\dagger}$ Excludes participants who did not reply; ${ }^{\dagger}$ Seoul, Incheon, and Gyeonggi Province; ${ }^{\S}$ Daejeon and North and South Chungcheong Provinces; "Daeju, North Gyeongsang Province, and Gangwon Province; "Busan, Ulsan, and South Gyeongsang Province; "Gwangju, North and South Jeolla Provinces, and Jeju; **For lead, blood heavy metal poisoning $>10 \mu \mathrm{g} / \mathrm{dL}$, for mercury, blood heavy metal poisoning $>5 \mu \mathrm{g} / \mathrm{L}$, for cadmium, blood heavy metal poisoning $>5 \mu \mathrm{g} / \mathrm{L} ; \mathrm{GM}=$ Geometric mean. 
Table 4. Blood Heavy Metal Concentrations According to Age at Menarche

\begin{tabular}{|c|c|c|c|c|c|c|}
\hline Variables & B & SE & $\mathrm{t}$ & $\mathrm{R}^{2}$ & Wald F & $p$ \\
\hline Lead $(\mu \mathrm{g} / \mathrm{dL})$ & 1.35 & 0.03 & 45.15 & .071 & 7.10 & $<.001$ \\
\hline 10 years* & -0.49 & 0.18 & 2.71 & & & .007 \\
\hline 11 years $^{\dagger}$ & -0.27 & 0.08 & 3.38 & & & .001 \\
\hline 12 years $^{\dagger}$ & -0.16 & 0.08 & 2.10 & & & .037 \\
\hline 13 years $^{\dagger}$ & -0.28 & 0.08 & 3.54 & & & .001 \\
\hline Mercury $(\mu \mathrm{g} / \mathrm{L})$ & 2.11 & 0.10 & 20.72 & .023 & 3.17 & .015 \\
\hline 10 years* & 0.03 & 0.49 & 0.06 & & & .951 \\
\hline 11 years $^{\dagger}$ & -0.47 & 0.22 & 2.14 & & & .033 \\
\hline 12 years $^{\dagger}$ & -0.39 & 0.14 & 2.77 & & & .006 \\
\hline 13 years $^{\dagger}$ & -0.07 & 0.29 & 0.26 & & & .797 \\
\hline Cadmium $(\mu \mathrm{g} / \mathrm{L})$ & 0.32 & 0.02 & 13.89 & .015 & 1.21 & .310 \\
\hline 10 years* & 0.12 & 0.09 & 1.34 & & & .182 \\
\hline 11 years $^{\dagger}$ & -0.04 & 0.04 & 1.13 & & & .262 \\
\hline 12 years $^{\dagger}$ & -0.02 & 0.03 & 0.70 & & & .486 \\
\hline 13 years $^{\dagger}$ & 0.10 & 0.10 & 0.97 & & & .332 \\
\hline
\end{tabular}

*Early-maturing: age at menarche less than 11 years; ${ }^{\dagger}$ Average-maturing: age at menarche between 11 and 13.

more than twice as high as those of similar-aged children in the North American region. In particular, mercury concentrations were almost five fold higher, and $1.5 \%$ of the subjects exceeded the $5 \mu \mathrm{g} / \mathrm{L}$ threshold that indicates poisoning according to the HBM standard [26], suggesting the need for more intensive control of children's mercury intake.

Mercury thermometers, plastic toys, houses and toys with paint containing heavy metals, and living in a deteriorated environment have been identified as significant factors affecting children's exposure to heavy metals [6]. In particular, children aged 7 18 in Korea spent 21 hours a day, on average, in indoor spaces such as houses and schools [27]. We can cautiously infer that such a living environment may have contributed to the elevated levels of blood heavy metal concentrations observed in Korean children. Recently, environmental pollution has received attention as a cause of heavy metal exposure. Pollution in the soil and air causes the accumulation of heavy metals in the ecosystem, and humans-as the apex of the food chain-ingest these food sources, leading to accumulations of heavy metals that are not eliminated through feces [1]. In Korea, the most prevalent route of environmental heavy metal exposure is the ingestion of food items produced in a contaminated environment [28]. Therefore, blood heavy metal concentrations in children are affected by the food they eat. For instance, the intake of grains, vegetables, fruits, fish, and shellfish tends to be higher in Korea than in the US, reflecting differences in culinary culture [27]. Therefore, eating habits may be a major factor contributing to the observed differences in blood heavy metal concentrations.

This study revealed that higher blood concentrations of lead and mercury were associated with lower ages at menarche. Exposure to endocrine-disrupting chemicals (EDCs) such as lead, cadmium, mercury, and polychlorinated biphenyls, among others [29], during the developmental stages of the central nervous system and sexual differentiation can alter the course of puberty [5,7]. Some EDCs mimic hormones, essentially tricking our body into thinking that they are hormones, while other EDCs block natural hormones from doing their job [5]. Exposure to lead interferes with various aspects of the hypothalamic-pituitary-gonadal axis, including the disruption of hormonal pathways, estradiol levels in females, luteinizing hormone levels, and follicle-stimulating hormone levels [5,7]. These commonly known environmental toxins act as EDCs in the body to promote early puberty [5,29]. This study showed no significant differences in age at menarche according to the participants' characteristics. Accordingly, early menarche in Korean girls is not caused by economic status, residential area, housing type, or obesity; however, environmental toxins that disturb sexual development can be considered as playing a causative role.

Prior studies showed a negative correlation between lead exposure and pubertal development in animals [30] and humans $[8,9,20]$. However, many results seem to contradict the findings of the present study. For instance, higher blood lead concentrations were found to delay the pubertal development of South African girls [20]. It was also reported that African-American girls and Mexican-American girls with higher blood mercury concentrations tended to experience a delayed onset of pubertal development [8], and high blood mercury concentrations were specifically found to be associated with significant delays in the development of pubic hair and menarche [9]. Several previous studies have reported that there were no significant relationships between blood mercury concentrations and pubertal development [18,19], which 
also did not correspond with the findings of the present study. Furthermore, previous research findings regarding cadmium concentrations and pubertal development are not consistent. A cohort study [10] in the US reported that high levels of urinary cadmium were associated with delayed menarche, but in a more recent study [11], Chinese girls who were exposed to cadmium showed early menarche.

We suggest that the discrepancies between previous research and this study can be explained in terms of differences in the research subjects (race), variation in physical and social environments, and the absolute levels of blood heavy metal concentrations. In the US, a significant difference was found in the correlations between blood heavy metal concentrations and the timing of menarche across Caucasian girls, African-American girls, and Mexican-American girls [8]. In the abovementioned study of Chinese girls, the relationship between the timing of menarche and the degree of heavy metal contamination varied depending on whether girls resided in an environment contaminated by heavy metals. The girls who resided in moderately or severely contaminated environments had a high risk of premature menarche before the age of 13 [11]. However, in our opinion, the most significant reason for the discrepancies between our findings and those of previous studies is the difference in the absolute levels of blood heavy metal concentrations. In studies reporting that higher blood heavy metal concentrations significantly delayed menarche, the concentrations were generally higher than in the subjects of this study, to the point that some were classified as experiencing heavy metal poisoning $[8,9]$.

Children and adolescents are often characterized as vulnerable populations susceptible to the adverse effects of environmental pollution. Therefore, they are usually at the forefront of environmental health policies. In the US and Germany, governments gather national biomonitoring data to track biological indicators regarding children's and adolescents' exposure to environmental hazards. Moreover, those governments assess a variety of national environmental health indicators as a basis for designing and promoting scientifically-grounded environmental health policies. However, the Korean government has insufficient means to assess children's and adolescents' exposure to environmental hazards through biological samples, despite the existence of nationwide sampling surveys such as the KNHANES and the Korean National Environmental Health Survey (KoNEHS). Those surveys are performed rather sporadically, instead of in a continuous way that would provide reliable monitoring information. Of even greater concern than the possibility that heavy metal exposure may induce premature menarche is the link between heavy metal exposure and elevated risks for various conditions related to female sex hormones [21]. When a child exposed to a contaminated environment grows into adulthood, she may suffer from subfertility or infertility, and she may be at a higher risk of obesity, hypertension, breast cancer, ovarian cancer, and endometrial cancer $[5,21]$. Hence, the issues that arise from exposure to hazardous materials during growth and development may result in a deteriorated quality of living, productivity, and social burden throughout the lifecycle of an individual.

Thus, extensive and ongoing nationwide surveys are needed to obtain data for assessing exposure to environmental hazards and the subsequent consequences for health; such data would help combat pollution, which is becoming an ever more severe problem, and would help prevent and control precocious puberty in Korean children. Since children are not yet physically mature, they require adults' protection and care. Because children's primary caretakers may exert an especially significant effect on their health, nationwide surveys should include both children and their family members, especially parents.

This study is subject to certain limitations due to its retrospective design. Furthermore, the KNHANES data do not contain information on breast or public hair development, which would be helpful for diagnosing precocious puberty in girls. Therefore, this study used only age at menarche as an indicator of precocious puberty. It was also not possible to analyze some other variables related to heavy metals and precocious puberty, such as diet, physical activity, and internal and external environmental factors (psychosocial status, living environment, and maternal age at menarche). Nevertheless, this study is significant in that it analyzed associations between blood heavy metal concentrations in Korean children and age at menarche, which had not been attempted previously, using representative national data, and it revealed that elevated lead and mercury levels increased the risk of precocious puberty.

\section{CONCLUSION}

The blood heavy metal concentrations in Korean girls and adolescents aged 10 18 were 2 5 times higher than has been reported in advanced countries. Fortunately, the blood lead and cadmium concentrations did not exceed the CDC recommendations. However, $1.5 \%$ of subjects showed blood mercury concentrations that exceeded the levels recommended by the HBM standard, meaning that the risk of health damage exceeded the expected level in sensitive individuals. A major problem found in this study is that Korean girls faced an increasing risk of precocious puberty, as they showed a younger age at menarche in response to higher blood lead and mercury concentrations.

Children and adolescents are still developing, and expo- 
sure to harmful substances in this period has an effect on lifetime health. Therefore, a systematic, ongoing monitoring system for heavy metals is needed at the national level. These findings should also spur an additional interest in the environment.

\section{Conflict of interest}

No existing or potential conflict of interest relevant to this article was reported.

\section{REFERENCES}

1. Emurotu JE, Onianwa PC. Bioaccumulation of heavy metals in soil and selected food crops cultivated in Kogi state, North Central Nigeria. Environmental Systems Research. 2017;6(1):1-9. https://doi.org/10.1186/s40068-017-0098-1

2. Myong JP. Health effects of particulate matter. The Korean Journal of Medicine. 2016;91(2):106-113.

https://doi.org/10.3904/kjm.2016.91.2.106

3. Taboada-Castro M, Diéguez-Villar A, Rodríguez-Blanco ML, Taboada-Castro MT. Agricultural impact of dissolved trace elements in runoff water from an experimental catchment with land-use changes. Communications in Soil Science and Plant Analysis. 2012; 43(1-2):81-87. https://doi.org/10.1080/00103624.2012.631421

4. Ministry of Environment. Fine dust, what is it? [Internet]. Sejong: Ministry of Environment; 2016 [cited 2016 April 1]. Available from: http://www.me.go.kr/ebook/159/\#page=1

5. World Helath Organization; United Nations Environment Programme. State of the science of endocrine disrupting chemicals 2012 [Internet]. Geneva: World Helath Organization, United Nations Environment Programme; 2013 [cited 2013 March 12]. Available from:

https://www.who.int/ceh/publications/endocrine/en/

6. Edelman C, Kudzma E, Mandle C. Health promotion throughout the life span. 8th ed. Maryland Heights: Elsvier Health Sciences; 2013. p. 415-416.

7. Nkomo P, Richter LM, Kagura J, Mathee A, Naicker N, Norris SA. Environmental lead exposure and pubertal trajectory classes in South African adolescent males and females. The Science of the Total Environment. 2018;628-629(1):1437-1445.

https://doi.org/10.1016/j.scitotenv.2018.02.150

8. Selevan SG, Rice DC, Hogan KA, Euling SY, Pfahles-Hutchens A, Bethel J. Blood lead concentration and delayed puberty in girls. The New England Journal of Medicine. 2003;348(16):1527-1536. https://doi.org/10.1056/NEJMoa020880

9. Wu T, Buck GM, Mendola P. Blood lead levels and sexual maturation in U.S. girls: The third national health and nutrition examination survey, 1988-1994. Environmental Health Perspectives. 2003; 111(5):737-741. https:// doi.org/10.1289/ehp.6008
10. Rull RP, Canchola AJ, Reynolds P, Horn-Ross PL. Urinary cadmium and the timing of menarche and pubertal development in girls. Journal of Adolescent Health. 2014;54(2):S10-S11.

https://doi.org/10.1016/j.jadohealth.2013.10.037

11. Chen X, Zhu G, Jin T. Effects of cadmium exposure on age of menarche and menopause. Toxics. 2017;6(1):1-5.

https://doi.org/10.3390/toxics6010006

12. O SJ. Particulate matter. Yonhapnews [Internet]. 2018 January 22 [cited 2018 January 25]. Latest. Available from: https://www.yna.co.kr/view/AKR20180121025400033

13. Park JS. $42 \%$ Increase in patients treated with precocious puberty in the last five years. Medicaltoday [Internet]. 2019 September 20 [cited 2019 September 26]. Politics. Available from: http://www.mdtoday.co.kr/mdtoday/index.html?no=365212

14. Kim HS. Update of precocious puberty. Journal of Korean Endocrine Society. 2008;23(3):165-173. https://doi.org/10.3803/jkes.2008.23.3.165

15. Kim JY, Shin MS, Kim SH, Seo JH, Ma HS, Yang YJ. Association of iron status and food intake with blood heavy metal concentrations in Korean adolescent girls and women: Based on the 2010 2011 Korea national health and nutrition examination survey. Journal of Nutrition and Health. 2017;50(4):350-360.

https://doi.org/10.4163/jnh.2017.50.4.350

16. Choi IS, Choi SC. Contents and migration of heavy metals and phthalates in children's products and phthalates in children's products. Journal of Korean Society of Environmental Engineers. 2014;36(2):127-138. https://doi.org/10.4491/KSEE.2014.36.2.127

17. Moon WJ, Kwon HJ, Hwang MK. The comparison of psycho-social behavior characteristics between girls with precocious puberty and normal girls. Journal of the Korea Academia-Industrial cooperation Society. 2018;19(2):357-369.

https://doi.org/10.5762/KAIS.2018.19.2.357

18. Hammerschmidt CR, Sandheinrich MB, Wiener JG, Rada RG. Effects of dietary methylmercury on reproduction of fathead minnows. Environmental Science and Technology. 2002;36(5):877-883. https://doi.org/10.1021/es011120p

19. Matta MB, Linse J, Cairncross C, Francendese L, Kocan RM. Reproductive and transgenerational effects of methylmercury or aroclor 1268 on fundulus heteroclitus. Environmental Toxicology and Chemistry. 2001;20(2):327-335.

https://doi.org/10.1002/etc.5620200213

20. Naicker N, Norris SA, Mathee A, Becker P, Richter L. Lead exposure is associated with a delay in the onset of puberty in South African adolescent females: Findings from the birth to twenty cohort. The Science of the Total Environment. 2010;408(21):49494954. https://doi.org/10.1016/j.scitotenv.2010.07.037

21. Biro FM, Pajak A, Wolff MS, Pinney SM, Windham GC, Galvez MP, et al. Age of menarche in a longitudinal US cohort. Journal of Pediatric and Adolescent Gynecology. 2018;31(4):339-345. https://doi.org/10.1016/j.jpag.2018.05.002 
22. Korea Centers for Disease Control and Prevention. The sixth Korea national health and nutrition examination survey (KNHANES VI) [Internet]. Sejong: Korea Centers for Disease Control and Prevention; 2013 [cited 2015 August 12]. Available from: https://knhanes.cdc.go.kr/knhanes/sub03/sub03_06_02.do

23. Ha MN. Heavy metal exposure status and health effects of Korean adolescents. 2015 Environmental Health and Toxicology Symposium and Conference; 2015 June 17-18; Jeju International Convention Center. Jeju: The Korean Society of Environmental Toxicology; 2015. p. 25-47.

24. Center for Disease Control and Prevention. Fourth national report on human exposure to environmental chemicals [Internet]. Northeast Atlanta: Center for Disease Control and Prevention; 2019 [cited 2019 January 30]. Available from:

https://www.cdc.gov/exposurereport/pdf/FourthReport_Upda tedTables_Volume1_Jan2019-508.pdf

25. Health Canada. Fourth report on human biomonitoring of environmental chemicals in Canada [Internet]. Ottawa: Health Canada; 2017 [cited 2017 August 23]. Available from:

https://www.canada.ca/en/health-canada/services/environme ntal-workplace-health/reports-publications/environmental-cont aminants/fourth-report-human-biomonitoring-environmental-c hemicals-canada.html

26. Schulz C, Wilhelm M, Heudorf U, Kolossa-Gehring M. Update of the reference and HBM values derived by the German human biomonitoring commission. International Journal of Hygiene and Environmental Health. 2011;215(1):26-35.

https://doi.org/10.1016/j.ijheh.2011.06.007

27. National Institute of Environmental Research. Korean exposure factors handbook for children [Internet]. Incheon: National Institute of Environmental Research; 2016 [cited 2016 April 20]. Available from:

http://webbook.me.go.kr/DLi-File/NIER/09/021/5609057.pdf

28. National Institute of Environmental Research. Environmental exposure and health survey in children and adolescents (IV) [Internet]. Incheon: National Institute of Environmental Research; 2014. [cited 2014 December 10]. Available from: http://webbook.me.go.kr/DLi-File/NIER/06/021/5592827.pdf

29. Greenspan LC, Lee MM. Endocrine disrupters and pubertal timing. Current Opinion in Endocrinology, Diabetes and Obesity. 2018;25(1):49-54. https://doi.org/10.1097/MED.0000000000000377

30. Dearth RK, Hiney JK, Srivastava V, Burdick SB, Bratton GR, Dees WL. Effects of lead (PB) exposure during gestation and lactation on female pubertal development in the rat. Reproductive Toxicology. 2002;16(4):343-352.

https://doi.org/10.1016/S0890-6238(02)00037-0 